examination and none of the five given unilateral ECT had any mention of handedness. Of particular concern was a patient who had mitral stenosis, where no mention was made of any physical findings beyond "mitral stenosis".

Was the patient reviewed weekly during a course of ECT?

Ten patients were not reviewed weekly; six of these were receiving out-patient ECT.

\section{Was the response to ECT documented in the notes?}

In ten casenotes no mention was made of response to ECT. Of the 40 who did have a mention, 19 showed a good response, 14 some improvement, five no change and two became manic.

Was the reason for stopping the course documented?

Eighteen notes gave no reason for stopping ECT. In some cases more than one reason for stopping ECT was given. Six patients withdrew consent, two stopped due to becoming manic, one because of a non-fatal cardiac arrest (the patient with mitral stenosis) and one because of prolonged confusion. Six patients stopped due to side-effects of ECT.

\section{Comment}

In a report to the Royal College of Psychiatrists, Pippard \& Ellam (1980) gave details of their prospective study in the use of ECT. There appeared to be few significant differences in demographic, illness and treatment details between this study and theirs apart from significantly fewer unilateral courses given in this study.

Although examination of medical notes is a somewhat crude measure of patient care, good documentation tends to reflect that thought has gone into treatment decisions. It was felt by all the medical staff who attended the audit presentation that there was considerable room for improvement in the documented management of ECT.

All aspects of the care of patients should be carefully considered and documented. The rationale for giving ECT, the response and reason for stopping are all important aspects of the total care of the patient. Special attention should be paid to those having out-patient ECT and arrangements should be made to have these patients regularly reviewed. The ECT prescription form should always be completed, and particular attention should be paid to patients who are physically unwell. Handedness should be specified in patients who have unilateral ECT.

The audit project allowed other issues concerning the administration of ECT to be reviewed. As part of a future study it was decided to time all fits as this has not been regularly done in the past. To complete the audit cycle a repeat audit is planned for six months time to see whether any improvements in practice have occurred.

\section{Reference}

Pippard, J. \& Ellam, L. (1981) Electroconvulsive Treatment in Great Britain, 1980. London: Gaskell (Royal College of Psychiatrists.

\title{
Medical audit among Scottish child psychiatrists
}

\author{
H. G. MoRton, Consultant Child Psychiatrist, Ninewells Hopsital, Dundee DD1 9SY; \\ R. J. R. McCABE, Consultant Adolescent Psychiatrist, Gartnavel Royal Hospital, \\ Glasgow; W. PARRY-Jones, Professor of Child and Adolescent Psychiatry, \\ Royal Hospital for Sick Children, Glasgow; and J. PICKETT, Senior Registrar in Child \\ Psychiatry, Ninewells Hospital Dundee
}

Working for Patients (DOH, 1989) has provided considerable impetus to the development of medical audit. The Royal College of Psychiatrists (1989) Preliminary Report on Medical Audit defined and distinguished between clinical audit, peer review and performance indicators, and referred to some of the particular problems affecting the development of audit in psychiatric practice. There are special concerns for child and adolescent psychiatrists developing medical audit programmes because of the wide diversity of child and adolescent practice and the considerable variability of resources in the subspecialty. Nicol (1989) has described the initial concern of the National Child Psychiatry Section's 
Working Group on audit with the Korner Report (HMSO, 1982) and the proposals on performance indicators outlined by the DHSS in 1987.

In 1989, the Child and Adolescent Psychiatry Section of the Scottish Division set up a working group to adapt the work of Nicol and his colleagues as a basis for the development of measures of activity particularly appropriate to Scottish working conditions. Subsequently, a pilot study of these measures was mounted, and analysis of data is currently in progress, in conjunction with the Information and Statistics Division of the Scottish Home and Health Department. Clinicians have recognised the need to be able to discuss with management the most appropriate measures of the quantity of work undertaken; however, uncertainty about the validity and accuracy of performance indicators as defined by Korner has been replaced by a greater appreciation of how analysis of the quality of medical care - the central core of medical audit-needs to become part of everyday practice. The Scottish Child and Adolescent Psychiatry Section Working Group concerned with performance indicators, therefore, modified its function early in 1990, and now acts as an audit group, the purpose of which is to encourage and support colleagues, particularly those outside the larger teaching centres, in their development of audit programmes. It was also envisaged that Scottish child and adolescent psychiatrists would find it helpful to have a forum for exchanging information about their audit activities.

As an initial step, the audit group circulated child and adolescent psychiatrists in Scotland to request information about the extent to which individual clinicians were involved in medical audit. At the time of this exercise, there were 38 consultants and 12 senior registrars in child and adolescent psychiatry in Scotland, and replies were obtained from $66 \%$ of consultants, and from the Scottish senior registrars as a group. It has been evident that many clinicians have regarded the setting up of data collection systems as a priority; there has been much concern with the development of appropriate data sets. In a number of centres, however, individual case studies are under way, regular audit of untoward clinical incidents takes place, and a variety of specific projects have been developed including a long-term follow-up of in-patients, a study of default from out-patient attendance, and a survey of 'consumer satisfaction'. An immediate concern centres on the difficulty which many colleagues in Scotland experience in reorganising clinical activity to make room for the development of formal audit procedures, and in finding secretarial and other staffing resources to implement and maintain suitable data systems. Supporting structures for medical audit vary in Scotland. Child and adolescent psychiatrists are able to obtain some practical support from management in the units in which they work, but direct involvement of specialists in public health medicine, through provision of epidemiological support, appears to be largely lacking.

The Scottish Child and Adolescent Psychiatry Section Audit Group has offered practical support and advice to colleagues wishing to make progress in developing their own audit activity. Three consultants, and one consultant in public health medicine have met with the audit group for this purpose. Medical audit is regularly on the agenda at Scottish Child and Adolescent Psychiatry Section meetings, and the group has recently published, for circulation within Scotland, a short newsletter, which acts as an information exchange by giving brief details of activities in different centres. A 'starter pack' on medical audit is being assembled, giving references to key papers on the subject, with annotations as appropriate. The next steps include an appraisal of how far medical audit in child and adolescent psychiatry has progressed in Scotland, with consideration of specific projects which may be appropriate to develop on a Scottish basis. In this, the group is encouraged by the formation of an Audit Committee of the National Child and Adolescent Psychiatry Section of the College.

\section{References}

Department of Health (1989) Working for Patients. London: HMSO.

DHSS (1987) Performance Indicators for the NHS. Services for the Mentally III. London: HMSO.

First Report of the Steering Group on Health Services Information (1982) London: HMSO.

Nicol, A. R. (1989) Performance indicators in child and adolescent psychiatry. Psychiatric Bulletin, 13, 94-97.

The Royal College of Psychiatrists (1989) Preliminary report on medical audit. Psychiatric Bulletin, 13, $577-580$. 